DOI: 10.12731/2070-7568-2018-2-7-25

УДК 06.77.90; 82.17.25

\title{
АНАЛИЗ ФОРМИРОВАНИЯ ИМИДЖА ОРГАНИЗАЦИИ-РАБОТОДАТЕЛЯ НА РЫНКЕ ТРУДА КАК ФАКТОРА ПРИВЛЕЧЕНИЯ ПОТЕНЦИАЛЬНЫХ РАБОТНИКОВ
}

\author{
Яркова С.А., Романцова Ю.Д., Якимова Л.Д., \\ Малахова A.A.
}

Имидж компании определяет восприятие, отношение и поведение как нанимаемых сотрудников, так и уже работающих в компании, а также он играет большую роль в укреплении или, наоборот, в разрушении их трудовой лояльности. В статье рассмотрена методика исследования одного из актуальных направлений маркетинга персонала, заключающегося в необходимости формирования положстельного и устойчивого имиджа компанииработодателя на рынке труда. Проведен анализ имиджа крупной российской компании, согласно которому выявлень следующие обстоятельства: более низкий уровень сформированности внешнего имиджа работодателя по сравнению с внутренним, наличие различий в восприятии работодателя у текущих и потенцииальных работников, а также большое количество негативных отзывов в сети Интернет.

В ичелях повышения привлекательности данной компании для потенциальных работников предложены следующие мероприятия по развитию имиджа: участие представителей организачии в тематических выставках и конференциях; организация дней открытых дверей; наполнение сайта организации интересующей потенциальных работников информацией; сотрудничество с кадровыми агентствами; участие в ярмарках вакансий; организация внутренних коммуникаций.

Цель - анализ имиджа компании железнодорожной отрасли. 
Метод или методология проведения работы: в статье использовались эмпирические методы, а также статистические методы анализа.

Результаты: определено состояние внешнего и внутреннего имиджа исследуемой компании и предложень мероприятия для его развития.

Область применения результатов: полученные результать целесообразно применять для повышения имиджа в организациях железнодорожной отрасли.

Ключевые слова: имидж работодателя; внутренний имидж; внешний имидж; рынок труда; привлечение персонала.

\section{ANALYSIS OF FORMING THE IMAGE OF THE ORGANIZATION-EMPLOYER ON THE LABOR MARKET AS A FACTOR OF ATTRACTING POTENTIAL WORKERS}

\section{Yarkova S.A., Romantsova Yu.D., Yakimova L.D., Malakhova A.A.}

The image of the company determines the perception, attitude and behavior of both hired employees and those already working in the company, and it plays a big role in strengthening or, conversely, in destroying their labor loyalty. The article examines the methodology for researching one of the current areas of marketing staff, which consists in the need to create a positive and sustainable image of the employer company in the labor market. The analysis of the image of a large Russian company was conducted, according to which the following circumstances were revealed: a lower level of formation of the external image of the employer compared to the internal one, differences in the perception of the employer among current and potential employees, as well as a large number of negative reviews on the Internet. In order to increase the attractiveness of this company for potential employees, the following measures are proposed to develop the image: participation 
of representatives of the organization in thematic exhibitions and conferences; organization of open days; filling the site of the organization of the potential workers interested in the information; cooperation with employment agencies; participation in job fairs; organization of internal communications.

The goal is to analyze the image of the railway company.

Method or methodology of the work: the article used empirical methods, as well as statistical methods of analysis.

Results: the state of the external and internal image of the company is determined and measures for its development are proposed.

Scope of application of the results: it is advisable to apply the results obtained to improve the image in the organizations of the railway industry.

Keywords: the image of the employer; internal image; external image; labor market; staff recruitment.

Имидж работодателя - это нематериальный актив фирмы, играющий важную роль при оценке того или иного места работы соискателями и действующими сотрудниками фирмы [1]. Иначе говоря, имидж представляет собой образ компании, который формируется в общественном и индивидуальном сознании. С точки зрения маркетинга персонала, имидж организации - это комплекс творческих, организационных, управленческих, и коммуникационных мероприятий, содействующих передаче во внешнюю среду набора позитивных образов и представлений о компании как работодателе, привлекающих к ней внимание соискателей свободных вакансий на рынке труда и возможных партнеров по бизнесу [2, 3, 4].

В настоящее время происходит переход от рынка «работодателя» к рынку «работника». Если ранее предприятия выбирали кандидатов и люди расценивались как ресурсы, то сегодня персонал становится самым главным капиталом, и право выбора лучших условий труда перешло к сотрудникам и соискателям рабочих мест [5, 6]. Кроме того, на предприятиях возникает необходимость в удержании высококвалифицированных кадров, способных передавать свой профес- 
сиональный опыт молодым сотрудникам $[7,8,9]$. Таким образом, в сегодняшней высококонкурентной борьбе за привлечение и удержание ключевых сотрудников именно имидж работодателя выходит на первый план, что обуславливает актуальность данной темы.

Впервые о теории развития имиджа работодателя заговорили в Англии в 1990 году, и сегодня данная тема активно развивается благодаря современным исследованиям. В 1996 г. понятие «имидж работодателя» применительно к функции управления человеческими ресурсами было использовано в статье Т. Амблера и С. Берроу. Необходимость в разработки концепции имиджа работодателя была связана с утратой эффективности традиционных инструментов управления персоналом для привлечения и удержания кадров. В зарубежном опыте давно утвердился термин в отношении организаций, обладающих благоприятным имиджем работодателя, «работодатель по выбору» [10].

В современной бизнес среде выделяют несколько типов имиджа работодателя $[11,12]$. Наиболее популярные классификации представлены на рисунке 1 .

Внутренний имидж работодателя - это то, как видят компанию её сотрудники. В частности, это совокупность представлений о компании как о работодателе, а также видение и психологическое восприятие, ориентированное на формирование у действующего персонала положительного либо отрицательного отношения к организации.

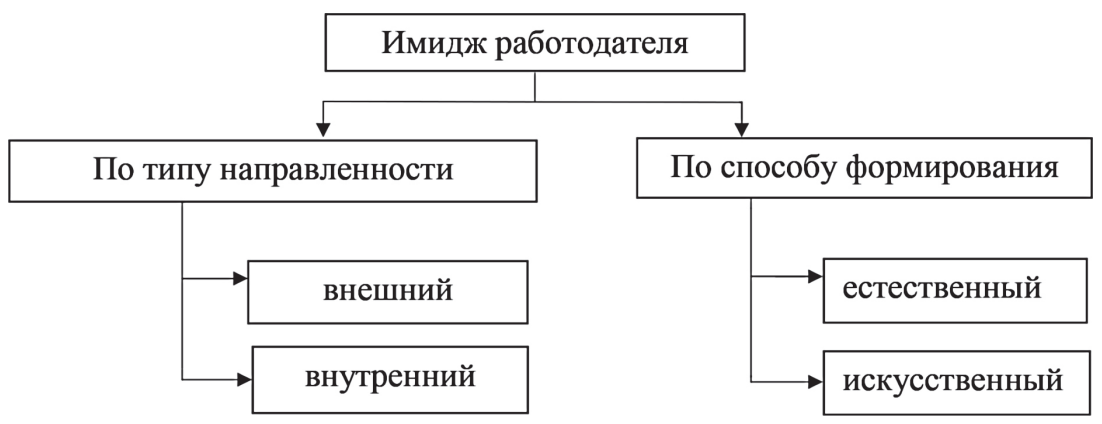

Рис. 1. Классификация имиджа организации-работодателя 
Кроме того, необходимо учитывать, что внутренний имидж достаточно сильно связан с внешним, так как именно действующий персонал организации является крупным носителем информации о фирме, о внутренней атмосфере и реальной работе. Внешний имидж - образ работодателя, сложившийся в сознании соискателей, кандидатов и потенциальных сотрудников. Внешний имидж, направлен на привлечение новых специалистов.

По способу формирования следует различать естественный и искусственный имидж работодателя. Первый формируется без усилий и спонтанно в результате практической деятельности организации, второй же формируется при помощи специально создаваемой рекламы либо благодаря постоянному совершенствованию.

Оценка имиджа организации-работодателя на рынке труда представляет собой совокупность исследований для выявления образа организации как работодателя и предоставления способов достижения её преимущественного положения на рынке труда [13].

Для выявления состояния имиджа ОАО «РЖД», проведем исследование по методике Л.А. Алексеевой [14] на основе индикаторного и балльного подхода, когда сначала предлагаются индикаторы, характеризующие организацию как работодателя на текущий момент, затем проводится оценивание с использованием рейтинговых и балльных методов. В качестве способов получения информации целесообразно использовать анкетирование.

Респондентами в данном случае выступали потенциальные работники (от 19 до 35 лет) - лица, занятые поиском работы, студенты-выпускники, формальные характеристики которых, такие как уровень и профиль образования отвечают требованиям организации, имидж которой оценивается и действующие сотрудники организации, в общей сложности в опросе приняло участие 60 человек. Респондентам были предложены 9 характеристик (индикаторов) организации-работодателя. Анкетируемым, в свою очередь, было необходимо оценить значимость для них индикаторов организации как работодателя, не допуская повторов оценок, методом прямого ранжирования от 1 до 9 (1 - наиболее значимая характеристика, 9 - 
наименее значимая характеристика). Далее респондентам следовало дать оценку привлекательности характеристикам организации-работодателя. Оценка индикаторов имиджа осуществлялась по трехбалльной шкале $\{0 ; 1 ; 2\}$ :

2 - предложенная характеристика привлекательна;

1 - предложенная характеристика скорее привлекательна;

0 - предложенная характеристика непривлекательна.

Результаты оценок всех респондентов сводятся в таблицу для обработки с целью расчета весовых коэффициентов оцениваемых характеристик. Результаты оценок значимости характеристик организации работодателя потенциальными сотрудниками отражены в таблице 1. Согласно полученным данным для потенциальных работников рассматриваемого предприятия наиболее значимыми характеристиками работодателя являются возможность профессионального развития и карьерного роста, а также уровень оплаты труда, ради которых потенциальные работники готовы жертвовать корпоративными нормами и традициями, которые получили самую низкую оценку значимости.

Далее респонденты оценивали по трехбалльной шкале привлекательность индикаторов, характеризующих. Результаты оценки привлекательности индикаторов, представлены в таблице 2.

Таблица 1.

Обработка результатов оценки значимости характеристик организации-работодателя потенциальными работниками

\begin{tabular}{|c|l|c|c|c|}
\hline $\begin{array}{c}\text { № } \\
\text { п/п }\end{array}$ & \multicolumn{1}{|c|}{$\begin{array}{c}\text { Характеристика } \\
\text { организации-работодателя }\end{array}$} & $\begin{array}{c}\text { Сумма } \\
\text { рангов }\end{array}$ & $\begin{array}{c}\text { Итоговый } \\
\text { ранг }\end{array}$ & $\begin{array}{c}\text { Весовой } \\
\text { коэффициент }\end{array}$ \\
\hline 1 & $\begin{array}{l}\text { Известность организации на рынке } \\
\text { труда }\end{array}$ & 155 & 5 & 0,11 \\
\hline 2 & $\begin{array}{l}\text { Принадлежность организации } \\
\text { к перспективной отрасли }\end{array}$ & 146 & 4 & 0,13 \\
\hline 3 & $\begin{array}{l}\text { Возможность профессионального } \\
\text { развития и карьерного роста }\end{array}$ & 101 & 1 & 0,20 \\
\hline 4 & $\begin{array}{l}\text { Стиль управления (характер } \\
\text { отношений между руководителями } \\
\text { и подсиненными) }\end{array}$ & 170 & 8 & 0,04 \\
\hline 5 & Корпоративные нормы и традиции & 174 & 9 & 0,02 \\
\hline
\end{tabular}


Окончание табл. 1.

\begin{tabular}{|c|l|c|c|c|}
\hline 6 & Содержание работы & 157 & 6 & 0,09 \\
\hline 7 & $\begin{array}{l}\text { Баланс совмещения работы } \\
\text { и личной жизни }\end{array}$ & 138 & 3 & 0,16 \\
\hline 8 & Компенсации и социальный пакет & 159 & 7 & 0,07 \\
\hline 9 & Уровень оплаты труда & 118 & 2 & 0,18 \\
\hline \multicolumn{2}{|c|}{ Сумма итоговых рангов } & 45 \\
\hline
\end{tabular}

Таблицуа 2.

Результаты оценки реального состояния характеристик организации на рынке труда

\begin{tabular}{|c|l|c|}
\hline $\begin{array}{c}\text { № } \\
\text { п/п }\end{array}$ & \multicolumn{1}{|c|}{ Характеристика организации-работодателя } & $\begin{array}{c}\text { Средняя } \\
\text { оценка }\end{array}$ \\
\hline 1 & Известность организации на рынке труда & 1,18 \\
\hline 2 & Принадлежность организации к перспективной отрасли & 1,34 \\
\hline 3 & Возможность профессионального развития и карьерного роста & 0,35 \\
\hline 4 & $\begin{array}{l}\text { Стиль управления (характер отношений между руководителями } \\
\text { и подсиненными) }\end{array}$ & 0,68 \\
\hline 5 & Корпоративные нормы и традиции & 1,02 \\
\hline 6 & Содержание работы & 0,78 \\
\hline 7 & Баланс совмещения работы и личной жизни & 0,93 \\
\hline 8 & Компенсации и социальный пакет & 1,27 \\
\hline 9 & Уровень оплаты труда & 1,29 \\
\hline
\end{tabular}

Данные таблицы 2 указывают, что индикатор «возможность профессионального развития и карьерного роста», являющийся очень весомым для опрошенных потенциальных работников, получил наименьшую оценку привлекательности $(0,35)$. Привлекательной характеристикой для большинства опрошенных является «принадлежность организации к перспективной отрасли».

На основании таблиц 1 и 2 необходимо рассчитать интегральный показатель сформированности внешнего имиджа организации-работодателя. Расчет значения интегрального показателя сформированности внешнего имиджа организации-работодателя представлен в таблице 3 .

Далее, таким же образом, был рассчитан интегральный показатель сформированности внутреннего имиджа организации-работодателя. Результаты оценок значимости характеристик организации работодателя действующими сотрудниками отражены в таблице 4. 
Таблицуа 3.

Расчет значения интегрального показателя сформированности внешнего имиджа организации-работодателя

\begin{tabular}{|c|c|c|c|c|}
\hline $\begin{array}{l}\text { № } \\
\Pi / \Pi\end{array}$ & $\begin{array}{c}\text { Характеристика } \\
\text { организации-работодателя }\end{array}$ & $\begin{array}{l}\text { Весовой ко- } \\
\text { эффициент } \\
\left(\mathrm{a}_{\mathrm{i}}\right)\end{array}$ & $\begin{array}{c}\text { Средняя } \\
\text { оценка } \\
\left(\mathrm{x}_{\mathrm{i}}\right)\end{array}$ & $\begin{array}{l}\text { Данные для } \\
\text { расчёта ин- } \\
\text { тегрального } \\
\text { показателя }\end{array}$ \\
\hline 1 & $\begin{array}{l}\text { Известность организации } \\
\text { на рынке труда }\end{array}$ & 0,11 & 1,18 & 0,13 \\
\hline 2 & $\begin{array}{l}\text { Принадлежность организации } \\
\text { к перспективной отрасли }\end{array}$ & 0,13 & 1,34 & 0,17 \\
\hline 3 & $\begin{array}{l}\text { Возможность профессионального } \\
\text { развития и карьерного роста }\end{array}$ & 0,20 & 0,35 & 0,07 \\
\hline 4 & $\begin{array}{l}\text { Стиль управления (характер } \\
\text { отношений между руководителями } \\
\text { и подсиненными) }\end{array}$ & 0,04 & 0,68 & 0,03 \\
\hline 5 & Корпоративные нормы и традиции & 0,02 & 1,02 & 0,02 \\
\hline 6 & Содержание работы & 0,09 & 0,78 & 0,07 \\
\hline 7 & $\begin{array}{l}\text { Баланс совмещения работы } \\
\text { и личной жизни }\end{array}$ & 0,16 & 0,93 & 0,15 \\
\hline 8 & Компенсации и социальный пакет & 0,07 & 1,27 & 0,09 \\
\hline 9 & Уровень оплаты труда & 0,18 & 1,29 & 0,23 \\
\hline \multicolumn{4}{|c|}{$\begin{array}{l}\text { Интегральный показатель сформированности внешнего имиджа } \\
\text { организации-работодателя (Сп) }\end{array}$} & 0,92 \\
\hline
\end{tabular}

Таблииа 4.

Обработка результатов оценки значимости характеристик организации-работодателя действующими сотрудниками

\begin{tabular}{|c|l|c|c|c|}
\hline $\begin{array}{c}\text { № } \\
\text { п/п }\end{array}$ & \multicolumn{1}{|c|}{$\begin{array}{c}\text { Характеристика } \\
\text { оргации-работодателя }\end{array}$} & $\begin{array}{c}\text { Сумма } \\
\text { рангов }\end{array}$ & $\begin{array}{c}\text { Итоговый } \\
\text { ранг }\end{array}$ & $\begin{array}{c}\text { Весовой } \\
\text { коэффициент }\end{array}$ \\
\hline 1 & $\begin{array}{l}\text { Известность организации } \\
\text { на рынке труда }\end{array}$ & 151 & 6 & 0,09 \\
\hline 2 & $\begin{array}{l}\text { Принадлежность организации } \\
\text { к перспективной отрасли }\end{array}$ & 142 & 8 & 0,04 \\
\hline 3 & $\begin{array}{l}\text { Возможность профессионального } \\
\text { развития и карьерного роста }\end{array}$ & 162 & 4 & 0,13 \\
\hline 4 & $\begin{array}{l}\text { Стиль управления (характер } \\
\text { отношений между руководителями } \\
\text { и подсиненными) }\end{array}$ & 157 & 5 & 0,11 \\
\hline 5 & Корпоративные нормы и традиции & 148 & 7 & 0,07 \\
\hline 6 & Содержание работы & 164 & 3 & 0,16 \\
\hline
\end{tabular}


Окончание табл. 4.

\begin{tabular}{|c|l|c|c|c|}
\hline 7 & $\begin{array}{l}\text { Баланс совмещения работы } \\
\text { и личной жизни }\end{array}$ & 168 & 2 & 0,18 \\
\hline 8 & Компенсации и социальный пакет & 134 & 9 & 0,02 \\
\hline 9 & Уровень оплаты труда & 173 & 1 & 0,20 \\
\hline \multicolumn{2}{|c|}{ Сумма итоговых рангов } & 45 \\
\hline
\end{tabular}

Для действующих сотрудников самыми актуальными характеристиками организаций-работодателей стали уровень оплаты труда, а также баланс совмещения работы и личной жизни, а наименее существенным - компенсации и социальный пакет.

Следующим этапом действующим сотрудникам следовало оценить реальное состояние характеристик организации на рынке труда. Результаты оценки отражены в таблице 5.

Таблица 5.

Результаты оценки реального состояния характеристик организации на рынке труда

\begin{tabular}{|c|l|c|}
\hline $\begin{array}{c}\text { № } \\
\text { п/п }\end{array}$ & \multicolumn{1}{|c|}{ Характеристика организации-работодателя } & $\begin{array}{c}\text { Средняя } \\
\text { оценка }\end{array}$ \\
\hline 1 & Известность организации на рынке труда & 1,86 \\
\hline 2 & Принадлежность организации к перспективной отрасли & 1,45 \\
\hline 3 & Возможность профессионального развития и карьерного роста & 0,94 \\
\hline 4 & $\begin{array}{l}\text { Стиль управления (характер отношений между руководителями } \\
\text { и подсиненными) }\end{array}$ & 0,41 \\
\hline 5 & Корпоративные нормы и традиции & 1,49 \\
\hline 6 & Содержание работы & 0,98 \\
\hline 7 & Баланс совмещения работы и личной жизни & 0,74 \\
\hline 8 & Компенсации и социальный пакет & 1,87 \\
\hline 9 & Уровень оплаты труда & 1,64 \\
\hline
\end{tabular}

Исходя из полученных данных таблицы 5 можно сделать вывод о том, что высокой оценки заслуживают такие характеристики как «компенсации и социальный пакет» и «известность организации на рынке труда». Наименьшая оценка зафиксирована по критерию «стиль управления».

Далее в таблице 6 произведен расчет значения интегрального показателя сформированности внутреннего имиджа организацииработодателя. 
Таблица 6.

Расчет значения интегрального показателя сформированности внутреннего имиджа организации-работодателя

\begin{tabular}{|c|c|c|c|c|}
\hline $\begin{array}{c}\text { № } \\
\Pi / \Pi\end{array}$ & $\begin{array}{c}\text { Характеристика } \\
\text { организации-работодателя }\end{array}$ & $\begin{array}{c}\text { Весовой } \\
\text { коэффициент } \\
\left(\mathrm{a}_{\mathrm{i}}\right)\end{array}$ & $\begin{array}{c}\text { Средняя } \\
\text { оценка } \\
\left(\mathrm{x}_{\mathrm{i}}\right)\end{array}$ & $\begin{array}{c}\text { Данные для } \\
\text { расчёта ин- } \\
\text { тегрального } \\
\text { показателя }\end{array}$ \\
\hline 1 & $\begin{array}{l}\text { Известность организации } \\
\text { на рынке труда }\end{array}$ & 0,09 & 1,86 & 0,18 \\
\hline 2 & $\begin{array}{l}\text { Принадлежность организации } \\
\text { к перспективной отрасли }\end{array}$ & 0,04 & 1,45 & 0,06 \\
\hline 3 & $\begin{array}{l}\text { Возможность профессионального } \\
\text { развития и карьерного роста }\end{array}$ & 0,13 & 0,94 & 0,12 \\
\hline 4 & $\begin{array}{l}\text { Стиль управления (характер } \\
\text { отношений между руководителями } \\
\text { и подсиненными) }\end{array}$ & 0,11 & 0,41 & 0,05 \\
\hline 5 & $\begin{array}{l}\text { Корпоративные нормы } \\
\text { и традиции }\end{array}$ & 0,07 & 1,49 & 0,10 \\
\hline 6 & Содержание работы & 0,16 & 0,98 & 0,16 \\
\hline 7 & $\begin{array}{l}\text { Баланс совмещения работы } \\
\text { и личной жизни }\end{array}$ & 0,18 & 0,74 & 0,13 \\
\hline 8 & $\begin{array}{l}\text { Компенсации и социальный } \\
\text { пакет }\end{array}$ & 0,02 & 1,87 & 0,04 \\
\hline 9 & Уровень оплаты труда & 0,20 & 1,64 & 0,33 \\
\hline \multicolumn{4}{|c|}{$\begin{array}{l}\text { Интегральный показатель сформированности внешнего имиджа } \\
\text { организации-работодателя (Cp) }\end{array}$} & 1,17 \\
\hline
\end{tabular}

Рассчитав интегральные показатели, следует сделать вывод о том, что значение показателя сформированности внутреннего имиджа работодателя $(1,17)$ превышает значение показателя сформированности внешнего имиджа организации $(0,92)$. С одной стороны, данный факт заслуживает положительной оценки так как внутренний имидж сформирован в большей степени в сравнении с внешним. Однако, исходя из условий методики, комбинация значений $(0 ; 2)$ характеризуется как неудовлетворительный результат. Тем самым возникает необходимость в совершенствовании имиджа организации на рынке труда.

Для наглядного восприятия результатов исследования необходимо обратиться к рисунку 2. 


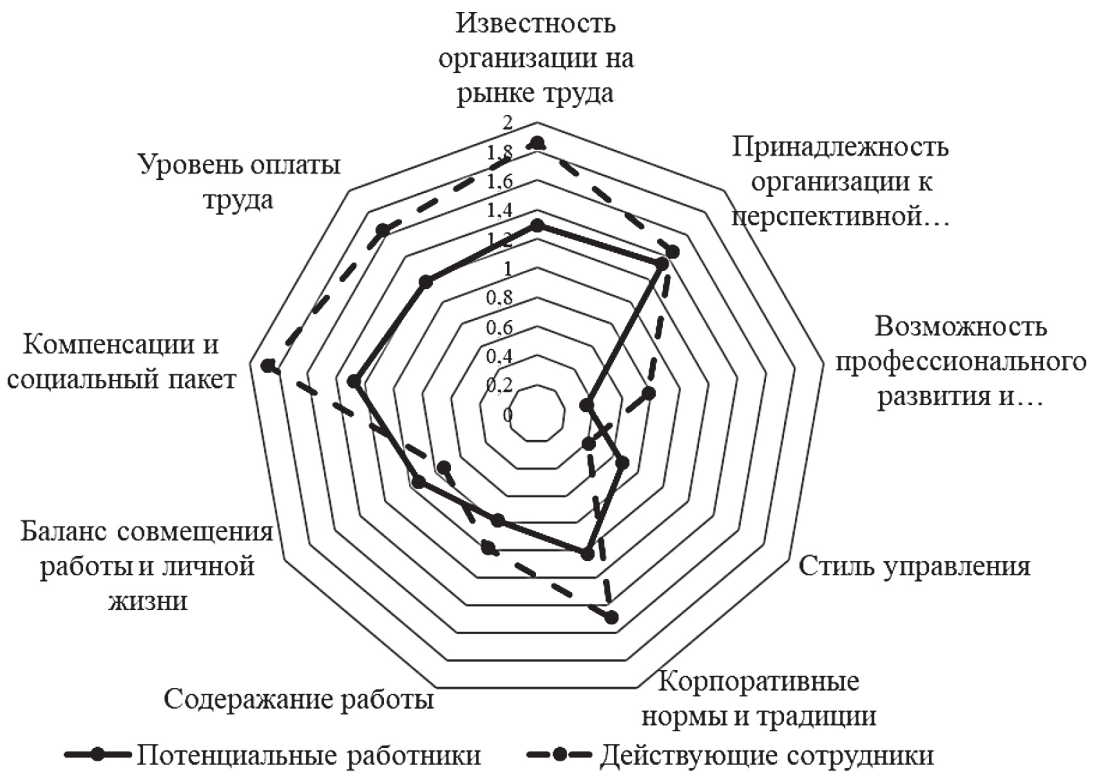

Рис. 2. Сравнение средних оценок потенциальных и действующих сотрудников

По рисунку 2, можно сказать, что наблюдается значительный разрыв между средними значениями оценки действующих и потенциальных работников, следовательно, большая часть оценок не совпадают. В случае, когда большинство оценок работников и соискателей не совпадают, предположительной причиной проблемы является некорректно сформированный и реализованный комплекс коммуникаций. То есть качество предложения работники оценивают высоко, но соискатели восприняли его как неудовлетворительное.

Конкретизировать причину неудовлетворительного состояния результативности коммуникации позволит мониторинг отзывов в сети Интернет как о работодателе. При поиске работы отзывы о компании в средствах массовой информации и на отраслевых сайтах являются основными источниками информации о работодателе соискателей интересует не столько официально распространяемые сведения, сколько мнения нынешних работников, бывших сотрудников, а также не прошедших собеседование кандидатов. 
В работе для оценки имиджа работодателя во внешней среде был проведён мониторинг репутации крупного предприятия железнодорожной отрасли. В качестве информационного поля были выбран Интернет сайт с наибольшим количеством отзывов, а именно электронная база отзывов и «indeed» (909 отзывов). В свою очередь, респондентам необходимо было оценить пять критериев по пятибалльной шкале, далее по каждому пункту рассчитывается средний балл.

Данный источник позволяет рассмотреть структуру отзывов по отношению к работодателю. Структура изображена на рисунке 3.

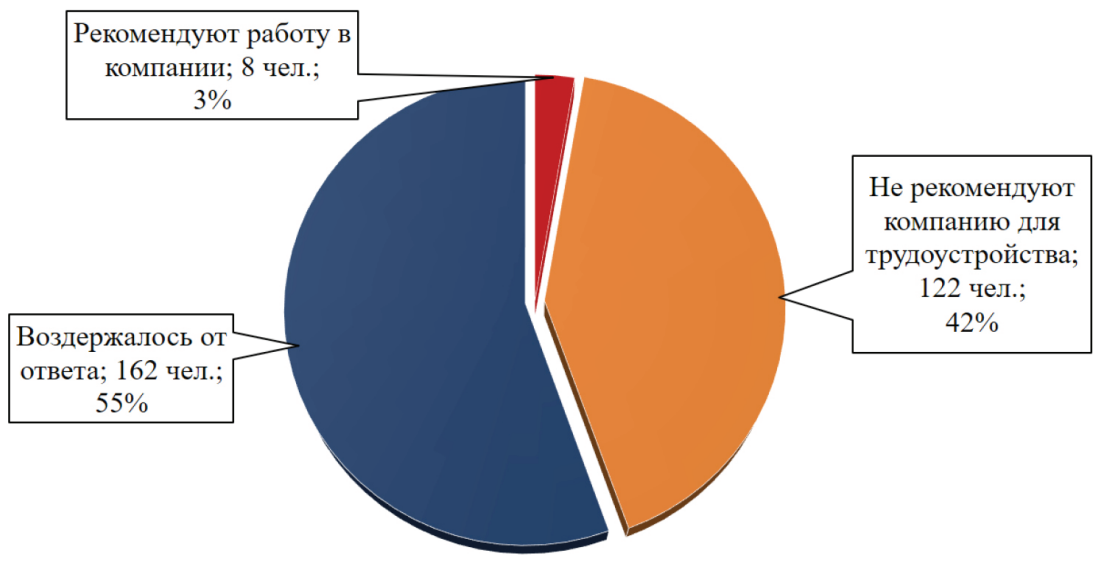

Рис. 3. Структура отзывов по отношению к работодателю

По рисунку 3, можно сделать вывод о том, что из 293 отзывов текущих и бывших работников 8 человек, а именно 3\% рекомендуют работу в компании, 122 человека (42\%) не рекомендуют компанию для трудоустройства и 55\% (162 человека) воздержалось от ответа. Для потенциального работника данная информация будет нести негативный характер, так как соискатель, прочитав множество отрицательных комментариев и фактов задумается над трудоустройством в данную организацию.

Далее подробно проанализируем отзывы в электронной базе «indeed». Данный источник позволяет оценить работодателя по следующим критериям: 
- баланс рабочего и свободного времени;

- компенсации;

- карьера и возможность продвижения;

- менеджмент;

- корпоративная культура.

Результаты исследования отзывов в электронной базе «indeed» отражены на рисунке 4.

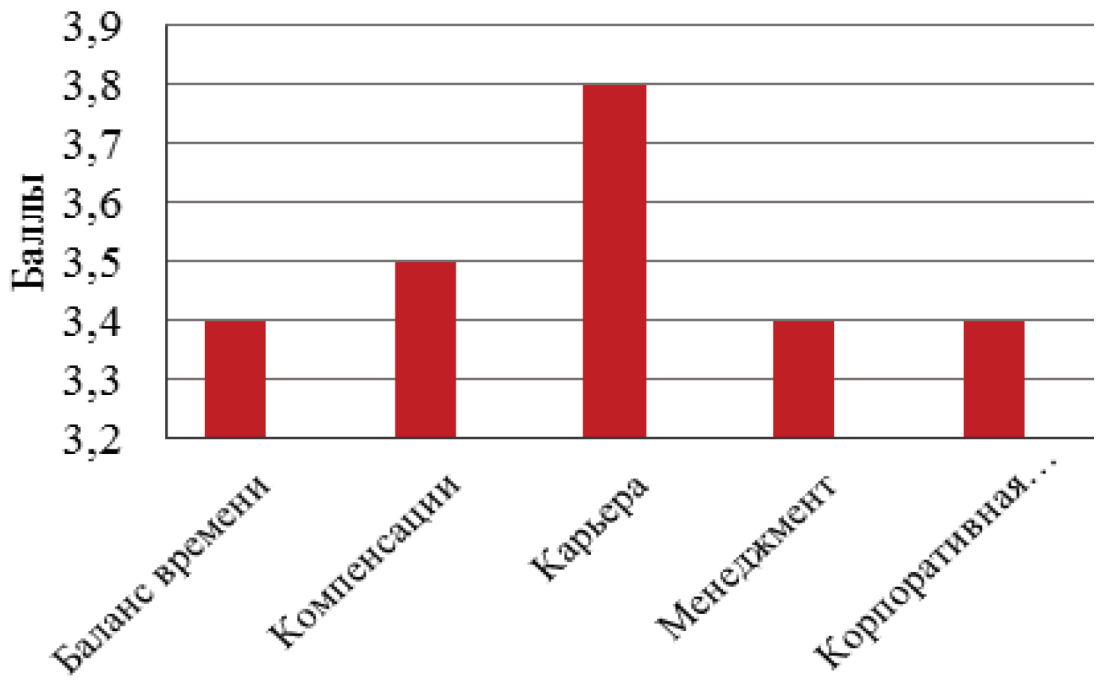

Рис. 4. Мнения о работодателе текущих и бывших работников в электронной базе отзывов «indeed»

Исходя из рисунка 5 необходимо отметить, что пункт «карьера и возможность продвижения» занимает наивысшую позицию - 3,8 балла, на втором месте расположен критерий «компенсации» $-3,5$ балла, и равное количество баллов характерны для таких позиций как баланс рабочего и свободного времени, менеджмент и корпоративная культура. Совокупный рейтинг работодателя по данным источника составляет 3,5 балла из пяти возможных.

По рисунку 5 можно сделать вывод о том, что большинство негативных отзывов на электронной базе «indeed» оставляют бывшие сотрудники организации. Высказывания о недовольстве уволенных 
работников отрицательно воздействуют на соискателя, так как кандидат прежде всего обращает внимание на негативные характеристики, чтобы избежать разочарования после трудоустройства. Тем самым внутренний имидж работодателя, представленный в отрицательных отзывах уволенных сотрудников сильно воздействует на формирование внешнего имиджа. Следовательно, чем больше негативных мнений, тем ниже интегральный показатель сформированности внешнего имиджа работодателя.

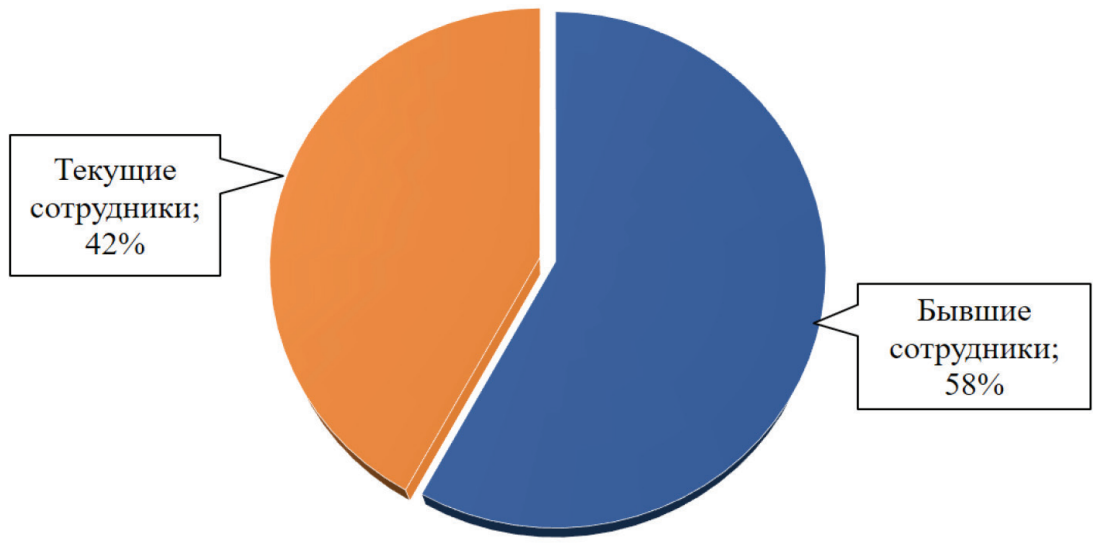

Рис. 5. Мнения о работодателе по целевым группам

На основании проведенной методики следует сделать вывод о том, что в организации существует проблема снижения привлекательности имиджа работодателя. Существование данной проблемы подтверждают такие факты как низкий уровень сформированности внешнего имиджа работодателя в сравнении с внутренним, различия в восприятии работодателя текущих и потенциальных работников, а также большое количество негативных отзывов в сети Интернет.

Для устранения данных проблем организации $[15,16]$ следует обратить внимание на совершенствование процесса реализации связей с общественностью [17]. Необходимо рекомендовать создание образа организации-работодателя в целом, продвижение «общего» предложения работодателя: 
- участие представителей организации в тематических выставках и конференциях;

- организация дней открытых дверей $[18,19]$;

- наполнение сайта организации интересующей потенциальных работников информацией;

- сотрудничество с кадровыми агентствами;

- участие в ярмарках вакансий;

- организация внутренних коммуникаций $[20,21]$.

Необходимо отметить, что стратегия развития данной компании предполагает переход от авторитарного стиля управления к демократическому. Но, так как эти процессы связаны с многолетними традициями и устоявшейся ментальностью трудовых, культурных и национальных отношений, то они осуществляются крайне медленно.

\section{Список литературы}

1. Бердинских М.В. Формирование имиджа организации: социологический анализ: автореферат дис. ... кандидата социологических наук: 22.00.04 / Бердинских Мария Викторовна; [Место защиты: Ур. федер. ун-т имени первого Президента России Б.Н. Ельцина]. Екатеринбург, 2013. 25 с.

2. Khalid, Shazia; Tariq, Shahnila. Impact of employer brand on selection and recruitment process // Pakistan Economic and Social Review. Volume 53, No. 2 (Winter 2015), pp. 351-372.

3. Минчингтон Б. HR-бренд: как стать лидером. Строим компанию мечты. М.: Юнайтед Пресс, 2014. 280 с.

4. Осовицкая H.A. HR-брендинг. Как стать лучшим работодателем в России. СПб.: Питер, 2015. 288 с.

5. Diab D. \& Highhouse, S. Corp Reputation Rev (2015) 18: 156. https:// doi.org/10.1057/crr.2015.10, pp. 156-173.

6. Луценко Е.Л., Николаева П.С. Управление трудоустройством в регионе // Наука Красноярья. 2015. № 5 (22). С. 101-110.

7. Шендель Т.В., Наумова А. Имиджевый профиль организации-работодателя: предпочтения потенциальных и работающих сотрудников 
// 120 лет железнодорожному образованию в Сибири: материалы Всероссийской научно-практической конференции с международным участием. Красноярск. 2014. C. 312-319.

8. Мансуров P.Е. HR-брендинг. Как повысить эффективность персонала. СПб.: БХВ-Петербург, 2016. 224 с.

9. Климчук А.А., Ливак Н.С. Имидж HR в борьбе за конкурентное преимущество // Управление человеческими ресурсами - основа развития инновационной экономики. 2013. № 4. С. 275-278.

10. Kissel P., Büttgen M. J Brand Manag (2015) 22: 755. https://doi. org/10.1057/bm.2015.42, pp. 755-777.

11. Выборова Т.Г. Формирование имиджа организации сферы услуг : автореферат дис. ... кандидата экономических наук: 08.00.05; [Mесто защиты: Сибирский университет потребительской кооперации]. Новосибирск, 2012. 20 с.

12. Опокин В.В. Формирование социального имиджа организации: (на примере компаний нефтегазового сектора): автореферат диссертации на соискание ученой степени кандидата социологических наук: специальность 22.00.03 Экономическая социология и демография / Виктор Валерьевич. Санкт-Петербург, 2013. 22 с.

13. Johnson M., Zinkhan G.M. (2015) Defining and Measuring Company Image. In: Dunlap B. (eds) Proceedings of the 1990 Academy of Marketing Science (AMS) Annual Conference. Developments in Marketing Science: Proceedings of the Academy of Marketing Science. Springer, Cham, pp. 346-350.

14. Алексеева Л. Методика оценки имиджа работодателя // Кадровик. 2010. № 4-2. С. 31-40.

15. Колединцева В.К., Романовская Е.Н., Мельникова Е.В. Финансовые и кадровые аспекты стратегии обеспечения устойчивости промышленного предприятия // Актуальные проблемы экономики и управления: Сборник научных трудов Международной научно-практической конференции. Санкт-Петербург, 2017. С. 110-114.

16. Вашко Т.А., Максименко И.А. Стратегия и конкурентоспособность // Стратегия предприятия в контексте повышения его конкурентоспособности. 2018. № 7 (7). С. 10-14. 
17. Титова С.В., Медведева Л.А. Подходы к пониманию сущности подбора, отбора и найма персонала // Наука Красноярья. 2017. Т. 6. № 1-2. С. 302-308.

18. Габидуллина Г.Р., Манаева И.Х., Рахимкулова Л.А. Проблема трудоустройства молодежи в контексте несоответствия рынка образовательных услуг и рынка труда // Наука Красноярья. 2015. № 6 (23). C. 89-96.

19. Нурутдинова А.Р., Дмитриева Е.В. Стратегическое партнерство как реализации инновационного взаимодействия вуза и технопарка // Наука Красноярья. 2012. № 5. С. 216-227.

20. Чаава М.3., Ливак Н.С. Руководитель как ключевое звено в системе управления персоналом // Архивариус. 2016. Т. 1. № 4 (8). С. $78-83$.

21.Данилова А.С., Федорова О.М., Здрестова-Захаренкова С.В. Развитие корпоративной культуры посредством эффективных коммуникаций организации // Вестник Северо-Кавказского федерального университета. 2016. № 2 (53). С. 42-47.

\section{References}

1. Berdinskih M.V. Formirovanie imidzha organizacii: sociologicheskij analiz [Formation of the organization's image: sociological analysis]: avtoreferat dis. ... kandidata sociologicheskih nauk : 22.00.04, Ekaterinburg, 2013. 25 p.

2. Khalid, Shazia; Tariq, Shahnila. Impact of employer brand on selection and recruitment process. Pakistan Economic and Social Review, 2015, vol. 53, no. 2, pp. 351-372.

3. Minchington B. HR-brend: kak stat'liderom. Stroim kompaniju mechty [HR-brand: how to become a leader. Building a Dream Company]. Moscow, 2014. 280 p.

4. Osovickaja N.A. HR-brending. Kak stat'luchshim rabotodatelem v Rossii [HR-branding. How to become the best employer in Russia], Saint-Petersburg, 2015. $288 \mathrm{p}$.

5. Diab D. \& Highhouse S. Corp Reputation Rev, 2015, pp. 156-173. https:// doi.org/10.1057/crr.2015.10 (accessed April 20, 2018). 
6. Lucenko E.L., Nikolaeva P.S. Nauka Krasnojar 'ja, no 5 (2015): 101-110.

7. Shendel' T.V., Naumova A. Imidzhevyy profil' organizatsii-rabotodatelya: predpochteniya potentsial'nykh i rabotayushchikh sotrudnikov [Image of the employer organization: preferences of potential and working employees]. 120 let zheleznodorozhnomu obrazovaniyu $v$ Sibiri: materialy Vserossiyskoy nauchno-prakticheskoy konferentsii s mezhdunarodnym uchastiem [120 years of railway education in Siberia: materials of the All-Russian scientific and practical conference with international participation]. Krasnoyarsk. 2014, pp. 312-319.

8. Mansurov R.E. HR-brending. Kak povysit' effektivnost' personala [HR-branding. How to improve staff efficiency]. SPb.: BKhV-Peterburg, 2016. $224 \mathrm{p}$.

9. Klimchuk A.A., Livak N.S. Upravlenie chelovecheskimi resursami-osnova razvitija innovacionnoj jekonomiki [Human resources management - the basis for the development of innovative economy], no 4 (2013): 275-278.

10. Kissel P. \& Büttgen M. J Brand Manag, 2015, pp. 755-777. https://doi. org/10.1057/bm.2015.42. (accessed April 20, 2018).

11. Vyborova T.G. Formirovanie imidzha organizacii sfery uslug [Formation of the image of the organization of services]: avtoreferat dis. ... kandidata jekonomicheskih nauk: 08.00.05, Novosibirsk, 2012. 20 p.

12. Opokin V.V. Formirovanie social'nogo imidzha organizacii: (na primere kompanij neftegazovogo sektora) [Formation of the social image of the organization: (by the example of companies in the oil and gas sector)]: avtoreferat dissertacii na soiskanie uchenoj stepeni kandidata sociologicheskih nauk: special'nost' 22.00.03, Sankt-Peterburg, 2013. 22 p.

13. Johnson M., Zinkhan G.M. Defining and Measuring Company Image. In: Dunlap B. (eds) Proceedings of the 1990 Academy of Marketing Science (AMS) Annual Conference. Developments in Marketing Science: Proceedings of the Academy of Marketing Science. Springer, Cham, 2015, pp. 346-350.

14. Alekseeva L. Kadrovik, no 4-2 (2010): 31-40.

15.Koledinceva V.K., Romanovskaja E.N., Mel'nikova E.V. Sbornik nauchnyh trudov Mezhdunarodnoj nauchno-prakticheskoj konferencii «Actual Problems of Economics and Management» [Financial and Per- 
sonnel Aspects of the Strategy for Ensuring the Sustainability of an Industrial Enterprise]. Sankt-Peterburg, 2017, pp. 110-114.

16. Vashko T.A., Maksimenko I.A. Strategija i konkurentosposobnost', no. 7 (2018): 10-14.

17. Titova S.V., Medvedeva L.A. Nauka Krasnojar'ja, vol 6, no 1-2 (2017): 302-308.

18. Gabidullina G.R., Manaeva I.H., Rahimkulova L.A. Nauka Krasnojar 'ja, no 6 (2015), pp. 89-96.

19. Nurutdinova A.R., Dmitrieva E.V. Nauka Krasnojar'ja ,no. 5 (2012): 216-227.

20. Chaava M.Z., Livak N.S. Arhivarius, vol 1, no 4 (2016): 78-83.

21.Danilova A.S., Fedorova O.M., Zdrestova-Zaharenkova S.V. Vestnik Severo-Kavkazskogo federal'nogo universiteta, no 2 (2016): 42-47.

\section{ДАННЫЕ ОБ АВТОРАХ}

Яркова Светлана Анатольевна, Романцова Юлия Дмитриевна, Якимова Любовь Дмитриевна, Малахова Анна Андреевна Красноярский институт железнодорожного транспорта филиал Иркутского университета путей сообщения lyubov-yakimova@yandex.ru

\section{DATA ABOUT THE AUTHORS}

Yarkova Svetlana Anatolevna, Romantsova Yuliya Dmitrievna, Yakimova Lyubov Dmitrievna, Malakhova Anna Andreevna Krasnoyarsk Institute of Railway Transport - branch of the Irkutsk Railway University lyubov-yakimova@yandex.ru 